\title{
The Effect of Heat Treatment on the Moisture Absorption Characteristics of Cu-Impregnated Masson's Pine Wood
}

\author{
Lamei Li, Guijun Xie, ${ }^{*}$ Wanju Li, Yixin Li, and Xingwei Li \\ The accumulation of water inside wood creates a favorable environment \\ not only for molds, but also for wood-decaying fungi and insects. \\ Therefore, the ability to limit water adsorption and retention is key to the \\ longevity and performance of wood. In this study, the effect of heat- \\ treatment and $\mathrm{Cu}$ nanoparticle (CuNP) impregnation on surface contact \\ angle, specific surface area, and hygroscopicity of Masson's pine wood \\ was examined. Heat-treatment caused thermal degradation of hydroxyl- \\ rich biopolymers, leading to an increase in hydrophobicity; while the \\ resulting breakdown and blockage of the interior cell cavity network \\ caused a decrease in effective surface area. In turn, the hygroscopicity of \\ the heat-treated wood was considerably lower than the untreated wood. \\ Analysis of water adsorption isotherms enabled the differentiation \\ between bound water and free water, where the latter was a prerequisite \\ for mold growth. The research showed that the amount of free water was \\ reduced by both impregnation with CuNP and heat-treatment, but the \\ previously observed antimicrobial activity was shown to rely on the \\ presence of CuNPs as opposed to the reduced free water content. This \\ study presented a detailed methodology for the preparation and analysis \\ of heat-treated, CuNP-impregnated wood, and provided further insight into \\ the mechanism of antimicrobial action of treated woods.
}

Keywords: Heat treatment; Masson's pine; Hygroscopicity; Specific surface area; Water contact angle; Dynamic moisture adsorption

Contact information: Guangdong Provincial Key Laboratory of Silviculture, Protection and Utilization, Guangdong Academy of Forestry, Guangzhou, 510520; *Corresponding author: xgj80@126.com

\section{INTRODUCTION}

Wood serves as the principle structural and water transport regulating component of trees. Both functions depend on the porous structure given by the cell cavities, intercellular layer, wood pits, and the large number of hydroxyl groups in the main chemical components cellulose, hemicelluloses, and lignin. As a result, wood is highly hygroscopic and therefore susceptible to both swelling and shrinkage, which affect the mechanical strength and the dimensional stability. At particularly high moisture contents, the wood interior becomes exceptionally favorable for the growth of molds such as Penicillium sp., Aspergillus sp., Trichoderma sp., and Stachybotrys sp. (Anagnost 2011). Excessive mold growth leads to the physical disruption of cell walls and the digestion of their biopolymer constituents. Mold initially causes wood mildew, but without any protective measures, mold proliferates and causes wood decay, which affects the mechanical properties of wood. It is widely accepted that hygroscopicity is a major limiting factor for the functional lifetime and value of wood (Van Meel et al.2011; Nair et al. 2017; Qing et al. 2017). 
Various methods have been developed for reducing the hygroscopicity of wood and lowering the internal surface area in order to protect the wood from attack by molds. Physical methods, such as surface coating and heat treatment, are cost-effective, non-toxic, and eco-friendly methods for reducing hygroscopicity of woods (Rowell 2005). For example, spruce wood (Picea abies) heat-treated at $210{ }^{\circ} \mathrm{C}$ exhibits reduced surface hydrophilicity due to the thermal degradation of surface-exposed hydroxy groups, which in turn explains a reduced hygroscopicity (Kutnar et al. 2013). Heat treatment also causes the degradation of cell walls, which destroys and blocks the internal porous network; and lowers the internal surface area.

Alternatively, surface-exposed hydroxyl groups can be effectively removed using chemical coating methods such as dipping, and chemical modification methods such as, cross-linking and acetylation treatments. For example, elm wood (Ulmus glabra) treated with acetic and maleic anhydride exhibits a large reduction in surface hydrophilicity as surface-exposed hydroxyl groups are converted into non-polar esters (Papadopoulos 2011). The hygroscopicity was significantly decreased in both cases, but the acetylation was more effective than the derivatization with maleic anhydride due to the better penetration of the smaller anhydride into the internal microporous network of wood. Similarly, the hygroscopicity of pine wood (Pinus sylvestris) is reduced by crosslinking surface-exposed hydroxyl groups with glutaraldehyde (Xie et al. 2011).

Recently, metal and metal oxide nanoparticles have gained popularity for treating wood for numerous reasons, but mainly because of their large effective surface area (Mohanraj and Chen 2006). For example, Masson's pine wood (Pinus massoniana) was impregnated with copper nanoparticles (CuNPs) by soaking the wood in a CuNP precursor before heat treatment (Xie et al. 2018). The susceptibility of the treated wood samples to damage caused by molds was substantially reduced; however, the mechanism of action was unidentified. In this paper, the potential link between antimicrobial activity and hygroscopicity of CuNP-impregnated and heat-treated Masson's pine wood was explored. Samples of Masson's pine wood were backfilled with CuNP precursor slurry containing $\mathrm{Cu}(\mathrm{OH})_{2}$, then heat-treated to yield CuNPs throughout the wood interior under controllable experimental conditions. The specific surface area, water contact angle, and water adsorption performance were then characterized to better understand the interaction between the treated wood and environmental water. A further aim was to understand the influences of CuNPs, heat treatment temperature, and time on the observed hygroscopicity and antimicrobial action. This study provides further insight into the underlying causes of the enhancement of the antimicrobial properties of wood by heat treatment, which is essential for improving the range of use and longevity of heat-treated wood.

\section{EXPERIMENTAL}

\section{Materials}

Wood samples

Fresh, mature sapwood from Masson's pine (Pinus massoniana) was sourced from 25-year-old trees with trunks of an average diameter of approximately $24 \mathrm{~cm}$, and an average tree height of approximately $16 \mathrm{~m}$. The wood showed no visible signs of decay or mildew. The wood was cut into two sizes of $25 \mathrm{~mm}$ (longitudinal; along the grain) $\times 20$ $\mathrm{mm} \times 5 \mathrm{~mm}$ and $50 \mathrm{~mm}$ (longitudinal) $\times 20 \mathrm{~mm} \times 5 \mathrm{~mm}$, and all test pieces were pretreated 
in an oven at $60{ }^{\circ} \mathrm{C}$ until their weight remained constant. All samples were obtained from the Xinyi City Forestry Research Institute, Guangdong Province (Xinyi, China).

\section{CuNP precursor solution $(\mathrm{CuG})$}

The $\mathrm{Cu}(\mathrm{OH})_{2}(6.35 \mathrm{wt} \%$ of the total precursor mass) was dissolved in a mixture of diethanolamine, polyethylene glycol 200, and water to yield a deep blue precursor solution denoted as $\mathrm{CuG}$. The proportions of the reagents were mixed according to a previously published protocol (Xie et al. 2018). The ratio of $\mathrm{Cu}(\mathrm{OH})_{2}$ to diethanolamine was 1:2; and the ratio of $\mathrm{Cu}(\mathrm{OH})_{2}$ to polyethylene glycol 200 was 1:0.5. First, $\mathrm{Cu}(\mathrm{OH})_{2}$ was dissolved with diethanolamine in water, which yielded a copper ammonia solution polyethylene glycol 200 was then added to yield CuG. All reagents were analytically pure and used as purchased from Tianjin Damao (Tianjin, China).

\section{Instruments}

The amount of water adsorbed by the treated wood samples was measured using a Vsorp basic dynamic vapor adsorption instrument (ProUmid GmbH \& Co. KG, Ulm, Germany), while the specific surface area was measured using a FINESORB-3020 specific surface and porosity analyzer (Zhejiang Finetech Instruments Co., Ltd., Quzhou, China). The contact angles of water droplets on treated wood surfaces were measured using a Theta T200 surface contact angle analyzer (Biolin Scientific AB, Gothenburg, Sweden). Wood samples were dried in a DHG-9240X drying oven (Shanghai Yiheng Scientific Instrument Co., Ltd., Shanghai, China), while heat treatment was conducted in a FB16137 heat treatment tank (Zhejiang Boiler Co., Ltd., Dongzhou, China). The pre-treatment experiment was conducted in a self-made pressure-holding tank.

\section{$\mathrm{CuG}$ pre-treatment protocol}

Approximately $2 \mathrm{~L}$ of $\mathrm{CuG}$ was poured into a pressure tank (customized equipment, mainly includes a container, an air pump, and a pressure gauge). Wood samples were then placed into the tank ensuring that they were completely immersed. The wood was allowed to soak for $30 \mathrm{~min}$ under vacuum, and then a pressure of $1.5 \mathrm{MPa}$ was applied and held for 40 min to degas the wood and allow $\mathrm{CuG}$ to fill the entire wood interior. The backfilled wood was then removed and dried at $60{ }^{\circ} \mathrm{C}$ in an oven until its weight remained constant.

\section{Heat Treatment Protocol}

The CuG-backfilled (R) and un-backfilled (D) wood samples were then subjected to heat treatment according to the different conditions outlined in Table 1. An untreated (no $\mathrm{CuG}$ or heating, referred to as $\mathrm{CK}$ ) samples was also reserved and analyzed for comparison.

\section{Sample loading}

A wood sample was placed in the heat treatment tank onto an inner wire net liner, which ensured that the sample was not in direct contact with the tank walls.

\section{Steam treatment}

After closing the heat treatment tank doors and valves, the steam generator pressure was set to $200 \mathrm{kPa}$. The steam was then allowed to enter the tank to a pressure of $100 \mathrm{kPa}$. The steam pressure was held for 20 min to ensure that all oxygen was evacuated from the pressure tank. 
Table 1. CuG Concentration, Carbonization Temperatures, and Times for Heattreated Wood Samples

\begin{tabular}{|c|c|c|c|}
\hline \multirow{2}{*}{ Sample } & \multicolumn{3}{|c|}{ Heat Treatment Conditions } \\
\cline { 2 - 4 } & $\mathrm{CuG}(\mathrm{wt} \%)$ & $\mathrm{T}\left({ }^{\circ} \mathrm{C}\right)$ & Heating Time $(\mathrm{h})$ \\
\hline CK & - & - & - \\
\hline $\mathrm{D} 1801$ & - & 180 & 3 \\
\hline $\mathrm{D} 1803$ & - & 180 & 5 \\
\hline $\mathrm{D} 1805$ & - & 180 & 7 \\
\hline D1807 & - & 180 & 1 \\
\hline D2001 & - & 200 & 3 \\
\hline D2003 & - & 200 & 5 \\
\hline D2005 & - & 200 & 7 \\
\hline D2007 & - & 200 & 1 \\
\hline D2201 & - & 220 & 3 \\
\hline D2203 & - & 220 & 5 \\
\hline D2205 & - & 220 & 7 \\
\hline D2007 & - & 220 & 3 \\
\hline R2203 & 6.35 & 220 & 5 \\
\hline R2205 & 6.35 & 220 & 7 \\
\hline R2207 & 6.35 & 220 & \\
\hline
\end{tabular}

\section{Carbonization}

The steam was then switched off, and the tank was heated to various temperatures and times according to Table 1 using an electric heating element, during which time the wood sample was carbonized.

After carbonization, the tank was cooled to below $140{ }^{\circ} \mathrm{C}$ by passing steam into the tank. The steam generator and heating element were then switched off, the pressure was carefully released by opening the gas outlet valve, and heat-treated wood sample was then removed.

\section{Characterization}

The specific surface area of all samples was estimated using the Brunauer Emmett and Teller (BET) nitrogen static volume method. The surface contact angle of water on wood samples was measured using the static drop method. The dynamic water sorption behavior of wood samples was examined by measuring the rate of mass change of mass under a controlled relative humidity $(\mathrm{RH})$ at $28{ }^{\circ} \mathrm{C}$. Adsorption was tested at $40 \%, 60 \%$, $70 \%, 80 \%, 85 \%$, and $90 \% \mathrm{RH}$, while desorption was tested at $90 \%, 85 \%, 80 \%, 70 \%, 60 \%$, $40 \%$, and $12 \% \mathrm{RH}$. For each RH condition, equilibrium moisture content was declared when the rate of mass change dropped below $0.06 \% / \mathrm{min}$ during a $2 \mathrm{~h}$ test. The water content was then calculated from Eqs. 1 and 2,

$$
\begin{aligned}
& M C=\frac{m_{2}-m_{1}}{m_{1}} \times 100 \\
& M C_{R}=\frac{m_{2}-m_{1}}{m_{0}} \times 100
\end{aligned}
$$

where $M C$ is the water content based on treated wood (\%), $M C_{\mathrm{R}}$ is the water content (\%) based on the wood prior to treatment, $m_{0}$ is the dry mass $(\mathrm{g})$ of the wood before treatment, $m_{1}$ is the dry mass $(\mathrm{g})$ of treated wood, and $m_{2}$ is the total mass $(\mathrm{g})$ of wood sample at equilibrium moisture content under the given $\mathrm{RH}$. 


\section{RESULTS AND DISCUSSION}

The change of the specific surface area of the heat-treated (Sample D) and untreated materials $(0 \mathrm{~h}$ heating time; Sample CK) were measured after treatment at different temperatures (Fig. 1). The specific surface area decreased as the heat treatment time increased. For example, the specific surface area decreased 20 to $25 \%$ after heating for 5 h. However, no obvious effects of heating temperature on the specific surface area were observed. The decrease in specific surface area was attributed to the expansion and seepage of retained resin into empty cell cavities, which formed blockages in the interior pore network. However, heating also caused degradation and/or vaporization of weaker organic compounds - particularly low-molecular products from hemicelluloses - in cell cavity walls, which created micropores and increased the specific surface area (Erçin and Yürüm 2003). This effect had a weaker influence on the overall specific surface area, but it may have caused the observed irregularities in the surface area measurements.

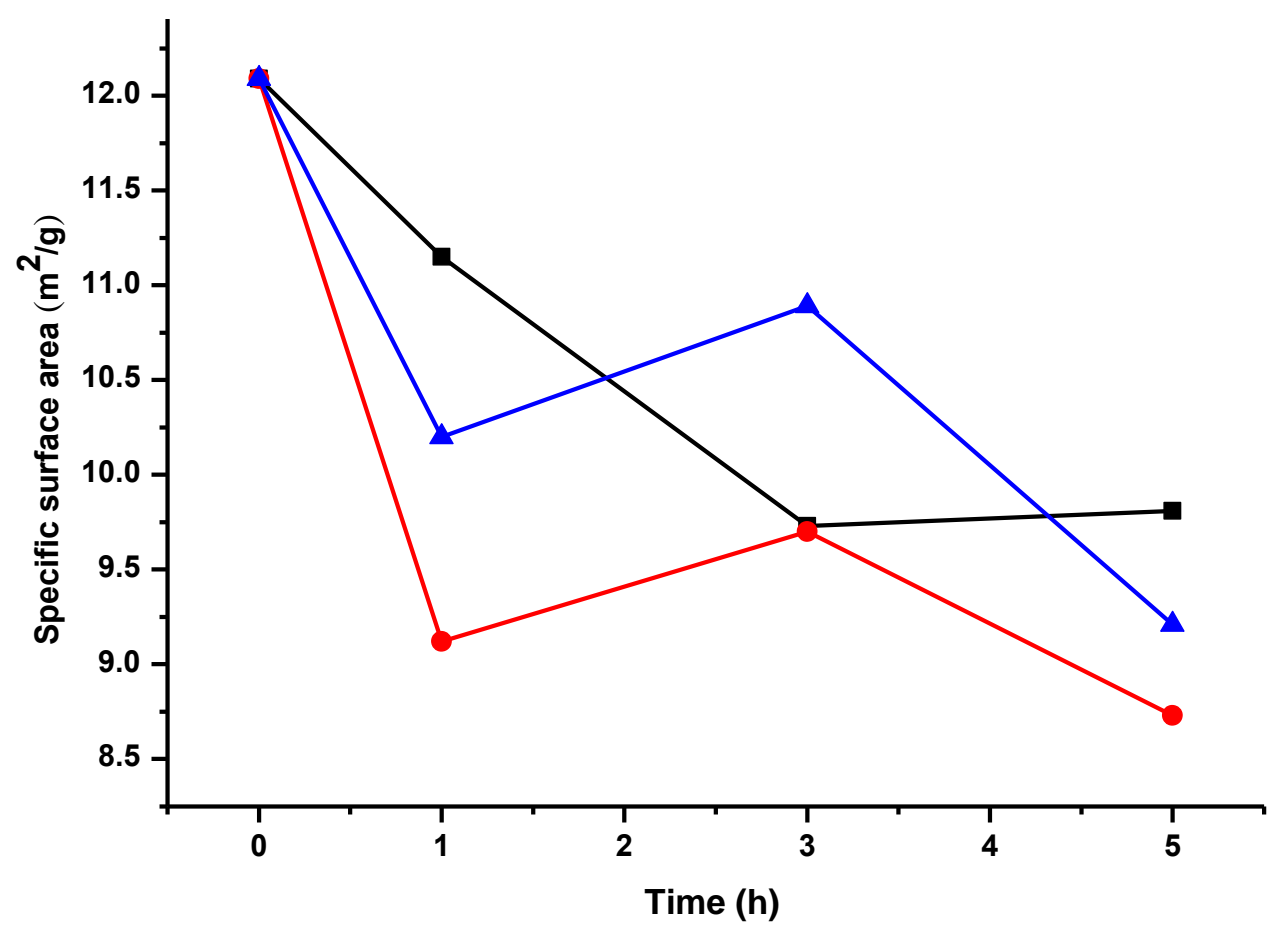

Fig. 1. The measured specific surface areas of Masson's pine wood samples heated for different times at different temperatures: $180^{\circ} \mathrm{C}$ (black square), $200^{\circ} \mathrm{C}$ (red circle), and $220^{\circ} \mathrm{C}$ (blue triangle)

Heat treatment was also shown to affect the wood surface hydrophilicity, where heating for only $1 \mathrm{~h}$ at $180{ }^{\circ} \mathrm{C}, 200{ }^{\circ} \mathrm{C}$, and $220^{\circ} \mathrm{C}$ led to a large increase in the surface contact angle of water from approximately $38^{\circ}$ to the range 83 to $87^{\circ}$ (Fig. 2). No remarkable effects of heating temperature on the contact angle were observed, and little change in contact angle was observed at extended heating times, where the angle was shown to increase by only 5 to $6^{\circ}$ between 1 and $5 \mathrm{~h}$ of heating. It was clear that only brief heating rendered the wood surface considerably more hydrophobic, which was signified by the increasing contact angle. This was attributed to the thermal degradation of the 
constituent biopolymers, which led to a large reduction in the number of polar, surfaceexposed hydroxyl groups.

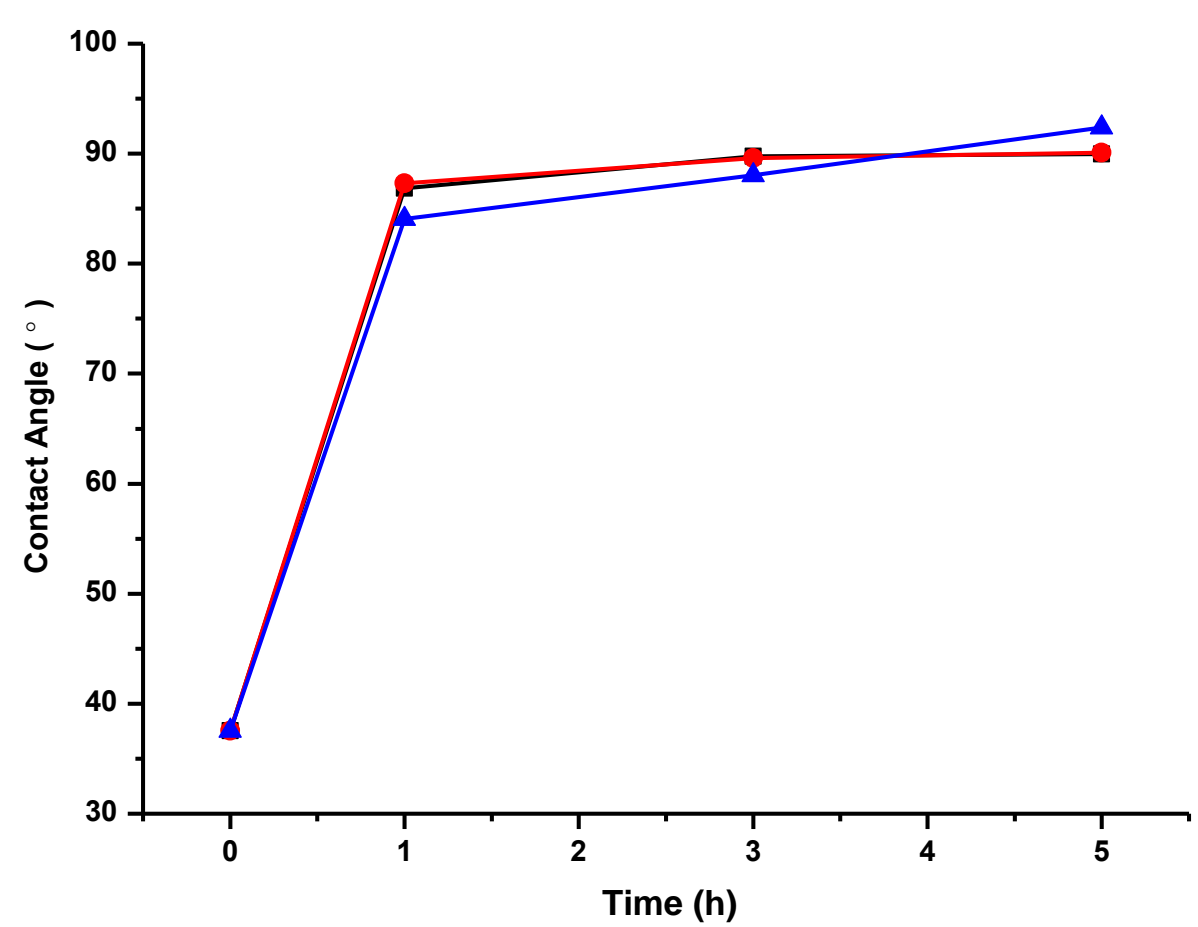

Fig. 2. Measured contact angles of water on the surfaces of Masson's pine wood samples heated for different times at different temperatures: $180^{\circ} \mathrm{C}$ (black square), $200^{\circ} \mathrm{C}$ (red circle), and 220 ${ }^{\circ} \mathrm{C}$ (blue triangle)

Both the decrease in specific surface area and the increase in contact angle suggested that the heat-treated wood should adsorb less water. A lower specific surface area, a smaller pore size, and an uneven pore morphology reduces the maximum water content (Chen et al. 2011). Meanwhile, a surface with an increased hydrophobicity, where the surface free energy with respect to water was higher, inhibited the mass transport of water by capillary action into the wood interior. In addition, blockages caused by the seepage of resin into the cell cavity network reduced the number of pathways through which the mass transport of water can take place. The linkages between both hydrophobicity and surface area, and water adsorption were then examined directly.

The percentage mass increase was analyzed for both heat-treated and untreated samples at different RH (Fig. 3). Water adsorption isotherms obtained from wood samples heat-treated at $180{ }^{\circ} \mathrm{C}, 200{ }^{\circ} \mathrm{C}$, and $220{ }^{\circ} \mathrm{C}$ showed that the values for equilibrium water contents based on treated wood (MC) expectedly increased with $\mathrm{RH}$, but also decreased as the heat treatment temperature increased. For example, when $\mathrm{RH}=90 \%$, the $\mathrm{MC}$ values were $13 \%, 9 \%, 8.5 \%$, and $7.5 \%$ for untreated, $180{ }^{\circ} \mathrm{C}, 200{ }^{\circ} \mathrm{C}$, and $220{ }^{\circ} \mathrm{C}$ samples, respectively. Meanwhile, equilibrium water contents based on the untreated wood $\left(\mathrm{MC}_{\mathrm{R}}\right)$ highlighted the influence of heat treatment time. For example, the isotherms obtained from samples heat treated at $180{ }^{\circ} \mathrm{C}$ and $220{ }^{\circ} \mathrm{C}$ revealed that $\mathrm{MC}_{\mathrm{R}}$ values decreased as the heat treatment time increased, which correlated well with surface area and contact angle data. It was noteworthy that the $\mathrm{MC}_{\mathrm{R}}$ isotherms for wood samples heat-treated at $200{ }^{\circ} \mathrm{C}$ revealed the same trend in $M_{R}$ values for samples heat-treated for 1, 3, and $5 \mathrm{~h}$; but that the $\mathrm{MC}_{\mathrm{R}}$ values increased after $7 \mathrm{~h}$. This is attributed to the pronounced onset of the degradation of 
hemicelluloses, but negligible degradation of cellulose, at $200{ }^{\circ} \mathrm{C}$ (Hakkou et al. 2006). After extended heat treatment times at $200{ }^{\circ} \mathrm{C}$, the microporosity of the wood increased dramatically as hemicelluloses degraded and outgassed, while the cellulose and lignin were retained (Erçin et al. 2003). These results suggested that $180{ }^{\circ} \mathrm{C}$ was insufficiently high for the complete degradation of hemicelluloses, but surface-exposed hydroxyls were lost and degraded. Meanwhile, $220^{\circ} \mathrm{C}$ was high enough to cause the extensive degradation of a large proportion of biopolymer constituents and the internal cell cavity structure, and to induce the strongest seepage of resin.
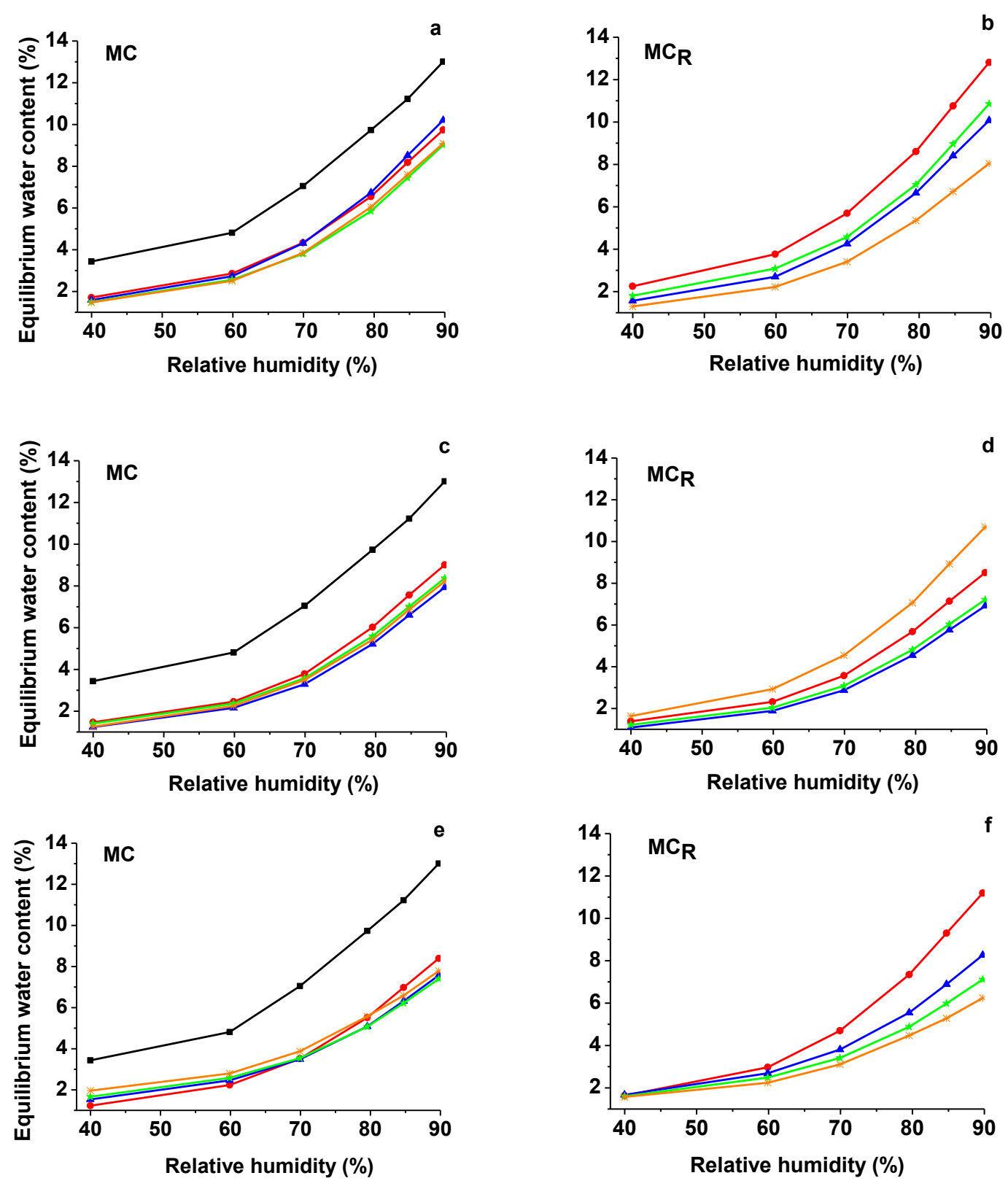

Fig. 3. The $M C$ (a, c, and e) and $M C_{R}(b, d$, and f) water adsorption isotherms measured from Masson's pine wood samples heat-treated at $180^{\circ} \mathrm{C}\left(\mathrm{a}\right.$ and b), $200^{\circ} \mathrm{C}$ (c and d), and $220^{\circ} \mathrm{C}(\mathrm{e}$ and f) for $1 \mathrm{~h}$ (red circle), $3 \mathrm{~h}$ (blue uptriangle), $5 \mathrm{~h}$ (green star), and $7 \mathrm{~h}$ (orange star ${ }^{\star}$ ). The untreated sample CK (black square) is also shown. 
The isotherms in Fig. 3 fit the Type II model sorption isotherm as defined by Venkateswaran (1970) and Simpson (1980). The isotherms were then further analyzed to distinguish between bound and free adsorbed water content. To achieve this, the HailwoodHorrobin (H-H) model that accounts for swelling during water adsorption, and the emergence of structuring of water when combined with biopolymers to yield hydrates, was used (Hailwood and Horrobin 1946). The model used assumed the formation of a single hydrate, and enabled the calculation of equilibrium constants for hydration, and the molecular mass of wood per water molecule from Eq. 3 (Yasuda et al. 1995),

$$
h / M=A+B h-C h^{2}
$$

and $\mathrm{A}, \mathrm{B}$, and $\mathrm{C}$ are defined by Eqs. 4, 5, and 6, respectively,

$$
\begin{aligned}
& A=\frac{W}{18 K_{2}\left(K_{1}+1\right)} \\
& B=\frac{K_{1}-1}{18\left(K_{1}+1\right)} \\
& C=\frac{K_{1} K_{2} W}{180000\left(K_{1}+1\right)}
\end{aligned}
$$

where $h$ is the $\mathrm{RH}(\%)$ and $M$ is the experimentally determined water content at equilibrium $(\%)$. The variable $K_{1}$ is the equilibrium constant for the adsorption of a water molecule from the liquid phase to the dry wood, whereas $K_{2}$ is the equilibrium constant between the liquid water phase and the surrounding water vapor. In other words, $K_{1}$ represents the bound water adsorbed by the biopolymer to yield the hydrate, while $K_{2}$ represents the free water throughout the wood interior. Finally, $W$ is the molecular weight of wood per mole of adsorbed water, or the inverse of the moisture content. Values for A, B, and C were obtained directly from the DVS studies, which were calculated using the least square method; and $K_{1}, K_{2}$, and $W$ were then expressed by Eqs. 7, 8, and 9 respectively:

$$
\begin{aligned}
& K_{1}=1+\frac{B^{2}+B \sqrt{B^{2}+4 A C}}{2 A C} \\
& K_{2}=\frac{50\left(-B+\sqrt{B^{2}+4 A C}\right)}{A} \\
& W=1800 \sqrt{B^{2}+4 A C}
\end{aligned}
$$

The calculated correlation coefficients $A, B, C$, and $r$; and values for $K_{1}, K_{2}$, and $W$ calculated from water adsorption isotherms obtained from heat-treated Masson's pine wood are summarized in Table 2. All untreated and heat-treated samples were shown to have a value for $r$ above 0.91, which suggested that the isotherms fit well to the $\mathrm{H}-\mathrm{H}$ model. As stated above, the model assumed that water was either bound in a polymer hydrate, or free within the cell cavities. Because mold growth depends on the free water, values for $K_{2}$ and $1 / W$ values are the most important for predicting antifungal properties (Chauhan et al. 2001). 
Table 2. Correlation Coefficients $A, B, C$, and $r$; Equilibrium Constants $K_{1}$ and $K_{2}$; and the Free Water Content $1 / W$ Calculated from Water Adsorption Isotherms Using Eqs. 3 to 9

\begin{tabular}{|c|c|c|c|c|c|c|c|c|c|}
\hline Sample & $\begin{array}{c}T \\
\left({ }^{\circ} \mathrm{C}\right)\end{array}$ & $A$ & $B$ & $C$ & $r$ & $K_{1}$ & $K_{2}$ & $W$ & $\begin{array}{c}1 / W \\
\left(10^{-5}\right)\end{array}$ \\
\hline $\mathrm{CK}$ & 28.0 & -687.30 & 20.66 & 0.14 & 0.91 & $1 . \overline{6}$ & 1.13 & 9168.63 & 10.90675 \\
\hline D1801 & 28.0 & $\begin{array}{c}- \\
1354.84 \\
\end{array}$ & 38.55 & 0.26 & 0.96 & $\begin{array}{l}- \\
1.51 \\
\end{array}$ & 1.13 & 14131.06 & 7.07661 \\
\hline D1803 & 28.0 & 1432.97 & 40.61 & 0.28 & 0.96 & 1.49 & 1.13 & 14511.04 & 6.891305 \\
\hline D1805 & 28.0 & $\begin{array}{c}- \\
1396.61\end{array}$ & 39.97 & 0.27 & 0.96 & 1.52 & 1.13 & 14946.28 & 6.690628 \\
\hline D1807 & 28.0 & 1585.30 & 45.04 & 0.31 & 0.96 & $\begin{array}{c}- \\
1.50 \\
\end{array}$ & 1.14 & 16194.64 & 6.174883 \\
\hline D2001 & 28.0 & $\begin{array}{c}- \\
2120.85\end{array}$ & 59.42 & 0.40 & 0.96 & 1.45 & 1.14 & 19827.16 & 5.043587 \\
\hline D2003 & 28.0 & 1881.14 & 53.26 & 0.36 & 0.96 & 1.49 & 1.14 & 18895.87 & 5.292162 \\
\hline D2005 & 28.0 & $\begin{array}{c}- \\
2101.22\end{array}$ & 58.99 & 0.40 & 0.96 & 1.46 & 1.14 & 20034.78 & 4.99132 \\
\hline D2007 & 28.0 & 1639.79 & 46.61 & 0.32 & 0.96 & 1.50 & 1.14 & 16847.52 & 5.935592 \\
\hline D2201 & 28.0 & $\begin{array}{c}- \\
1564.14 \\
\end{array}$ & 44.56 & 0.30 & 0.96 & 1.50 & 1.14 & 16240.24 & 6.157544 \\
\hline D2203 & 28.0 & $\begin{array}{c}- \\
1928.65\end{array}$ & 54.60 & 0.37 & 0.96 & 1.49 & 1.14 & 19384.70 & 5.158708 \\
\hline D2205 & 28.0 & $\begin{array}{c}- \\
2053.68 \\
\end{array}$ & 57.95 & 0.39 & 0.97 & $1 . \overline{48}$ & 1.14 & 20303.08 & 4.925361 \\
\hline D2207 & 28.0 & $\begin{array}{c}- \\
1143.38\end{array}$ & 34.25 & 0.24 & 0.92 & $1 . \overline{6}$ & 1.12 & 15309.24 & 6.532003 \\
\hline R2203 & 28.0 & 1060.40 & 32.29 & 0.23 & 0.91 & 1.70 & 1.13 & 15088.92 & 6.62738 \\
\hline R2205 & 28.0 & 1040.30 & 31.83 & 0.23 & 0.91 & $\begin{array}{c}- \\
1.72 \\
\end{array}$ & 1.13 & 15155.39 & 6.598313 \\
\hline R2207 & 28.0 & 1018.33 & 31.09 & 0.22 & 0.90 & 1.70 & 1.13 & 14484.97 & 6.903708 \\
\hline
\end{tabular}

Generally, $K_{2}$ was relatively consistent across all samples, which suggested that the exchange between the water vapor and the liquid water internalized by the wood samples did not change as the heat treatment conditions changed. However, values for $1 / W$ for all heat-treated (D) samples were considerably lower than those of the untreated (CK) sample, which suggested that the free water content decreased with heat treatment. Values for $1 / W$ dropped overall as the heat treatment temperature increased from $180{ }^{\circ} \mathrm{C}$ to $200{ }^{\circ} \mathrm{C}$, but little further change was observed at the higher heat treatment temperature of $220{ }^{\circ} \mathrm{C}$. Additionally, the $1 / W$ tended to decrease with heat treatment time, particularly for those heated at $180{ }^{\circ} \mathrm{C}$. Although the $1 / W$ decreased as the heat treatment time increased for samples heated at $200{ }^{\circ} \mathrm{C}$ and $220^{\circ} \mathrm{C}$, the $1 / \mathrm{W}$ value then increased at $7 \mathrm{~h}$ heating time. The authors' analysis of the water adsorption isotherms suggested that the optimal heat treatment conditions for resisting water adsorption were $220{ }^{\circ} \mathrm{C}$ for $5 \mathrm{~h}$.

The CuNP-impregnated Masson's pine wood samples prepared using heat treatment at $220^{\circ} \mathrm{C}$ for 3,5 , or $7 \mathrm{~h}$ were then analyzed to examine the influence of included 
CuNPs on water adsorption. The successful penetration of $\mathrm{CuG}$ into the entire wood interior, and the subsequent synthesis of CuNPs during heat treatment under the same conditions, have been previously demonstrated and described (Xie et al. 2018). Meanwhile, the water adsorption isotherms revealed that the CuNP-impregnated heat-treated wood adsorbed less water than the untreated sample (CK) (Fig. 4). The $\mathrm{MC}_{\mathrm{R}}$ isotherms suggested that the equilibrium water content decreased as the heat treatment time increased, such that the equilibrium water contents at $\mathrm{RH}=90 \%$ were $\approx 7 \%, \approx 8 \%$, and $\approx 11 \%$ at 3,5 , and $7 \mathrm{~h}$ heating time, respectively. Because resistance to water adsorption was improved most after only $3 \mathrm{~h}$ heat treatment time suggested that CuNP impregnation increased the efficiency of the heat treatment process.

The isotherms fit into the $\mathrm{H}-\mathrm{H}$ model $(\mathrm{r}=0.9)$ (Table 2$)$. While $K_{2}$ did not change with heat treatment time as expected, $1 / W$ decreased slightly between 3 and $5 \mathrm{~h}$ heating time, only to increase again slightly at $7 \mathrm{~h}$. However, the $1 / W$ values were larger than those from $\mathrm{CuNP}$-free wood samples, which suggested that the introduction of CuNPs slightly increased the free water content. This was attributed to the ability for metal salts to catalyze the carbonization process, which increased the content of high surface areas carbon microspheres, which moderately promoted the adsorption of water (Kang et al. 2012).

The authors' data showed that heat treatment of Masson's pine wood remarkably increased the resistance to water adsorption by increasing the surface free energy and preventing mass transport of water throughout the cell cavities. Although a lower free water content was known to prevent deleterious mold growth in wood, the authors suggested that this was not likely to be the main antimicrobial effect in the current case, because previous mildew growth studies indicated that the heat-treatment itself did not improve the antimicrobial behavior (Xie et al. 2018). Additionally, Xie et al. (2018) also demonstrated that the impregnation of wood with CuNPs greatly enhanced the antimicrobial behavior of Masson's pine wood. Because the current data confirmed that impregnation with CuNPs did not increase the resistance to water adsorption substantially, water adsorption properties were unlikely to be the reason for the observed enhanced antimicrobial action. Instead, the CuNPs could themselves have antimicrobial properties that either prevent or interfere with mold growth (Husen and Jawaid 2020). This is the subject of further investigation.
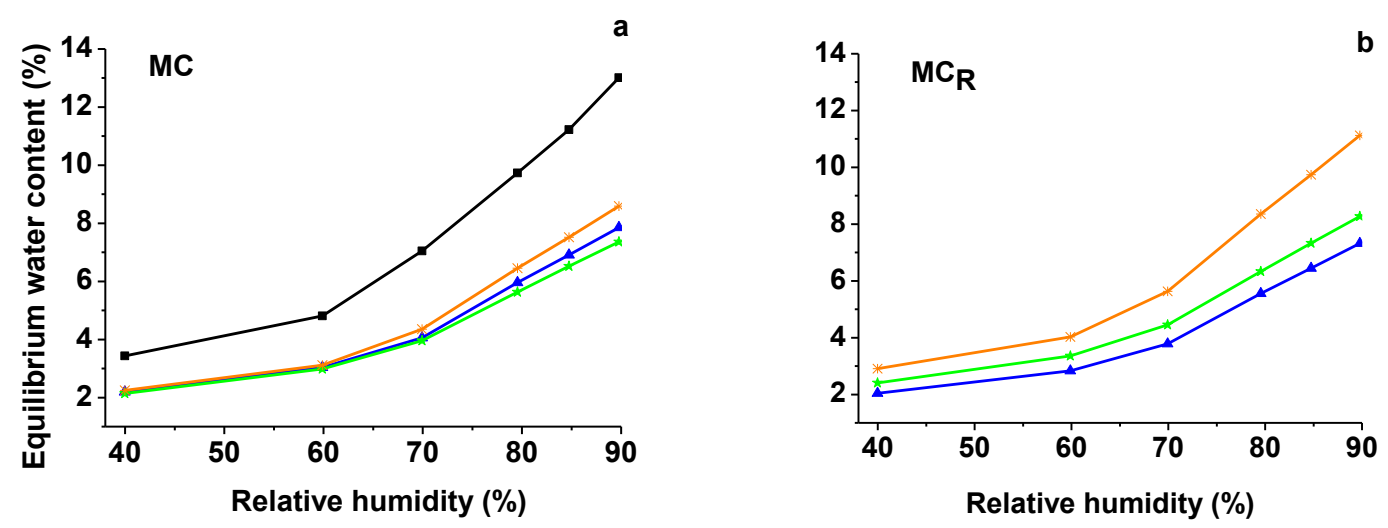

Fig. 4. $M C$ (a) and $M C_{R}(b)$ water adsorption isotherms measured from CuNP-impregnated Masson's pine wood samples heat-treated at $220^{\circ} \mathrm{C}$ for $3 \mathrm{~h}$ (blue triangle), $5 \mathrm{~h}$ (green star), and 7 $\mathrm{h}$ (orange star $^{*}$ ). The untreated sample CK (black square) is also shown. 


\section{CONCLUSIONS}

1. The high-temperature heat treatment protocol was shown to be an effective method for reducing the hydrophilicity of Masson's pine wood surfaces, which in turn reduced the hygroscopicity.

2. Extensive analysis of the state and nature of adsorbed water was then conducted by obtaining water adsorption isotherms, which were then used to differentiate between the contents of bound, structured water, and free water. When heat-treated wood samples, with and without CuNPs, were equilibrated under humid conditions, the total water contents were remarkably lower than those of untreated wood. The analysis revealed that heat treatment at $220{ }^{\circ} \mathrm{C}$ for 3 to $7 \mathrm{~h}$ yielded highest resistance to water adsorption. Additionally, the heat treatment process was enhanced by impregnated CuNPs, such that optimal resistance to water adsorption was achieved at shorter heat treatment times.

3. In a thorough investigative study, the authors' work not only highlighted the potential use of heat treatment and CuNP impregnation in controlling the hygroscopicity of wood, but also demonstrated that the antimicrobial properties of CuNP-impregnated Masson's pine wood was not directly linked to water adsorption and the internalized free water content. This study introduced a methodology for the comprehensive assessment of hygroscopicity of wood samples and provided further insight into the antimicrobial properties of CuNPs.

\section{ACKNOWLEDGEMENTS}

This research was jointly sponsored by the Guangdong Forestry Science and Technology Innovation Project "Research on the thermal modification of eucalyptus and Spingbract chinkapin wood and the key technologies of their wood flooring preparation (2018KJCX006)," and the Provincial Science and Technology Research Project of Guangdong "Research on the mechanism of mildew growth on heat treated wood and its preventive treating method (2014A040401043)."

\section{REFERENCES CITED}

Anagnost, S. (2011). "Wood decay, fungi, stain and mold," ESF SUNY College of Environmental Science and Forestry, (https://www.esf.edu/nekda/documents/WoodDecay-Anagnostsmallversion_000.pdf), Accessed 20 April 2019.

Chauhan, S. S., Aggarwal, P., Karmarkar, A., and Pandey, K. K. (2001). "Moisture adsorption behaviour of esterified rubber wood (Hevea brasiliensis)," Holz als Rohund Werkstoff 59, 250-253. DOI: 10.1007/s001070000152

Chen, J., Tan, P., and Wang, J. (2011). "Characterization of pore structure and specific surface area based on gas adsorption applied for porous materials," Powder Metallurgy Industry 21, 45-49. 
Erçin, D., and Yürüm, Y. (2003). "Carbonisation of fir (Abies bornmulleriana) wood in an open pyrolysis system at 50-300 ${ }^{\circ} \mathrm{C}$," Journal of Analytical \& Applied Pyrolysis 67(1), 11-22. DOI: 10.1016/S0165-2370(02)00011-6

Hailwood, A. J., and Horrobin, S. (1946). "Absorption of water by polymers: Analysis in terms of a simple model," Transactions of the Faraday Society 42, B084-B092. DOI: 10.1039/tf946420b084

Hakkou, M., Pétrissans, M., Gérardin, P., and Zouzalian, A. (2006). "Investigations of the reasons for fungal durability of heat-treated beech wood," Polymer Degradation \& Stability 91(2), 393-397. DOI: 10.1016/j.polymdegradstab.2005.04.042

Husen, A., and Jawaid, M. (2020). Nanomaterials for Agriculture and Forestry Applications, Elsevier Science Publishing Co., Int., New York, NY, USA.

Kang, S., Li, X., Fan, J., and Chang, J. (2012). "Characterization of hydrochars produced by hydrothermal carbonization of lignin, cellulose, d-xylose, and wood meal," Industrial \& Engineering Chemistry Research 51(26), 9023-9031. DOI: 10.1021/ie300565d

Kutnar, A., Kričej, B., Pavlič, M., and Petrič, M. (2013). "Influence of treatment temperature on wettability of Norway spruce thermally modified in vacuum," Journal of Adhesion Science and Technology 27(9), 963-972. DOI: 10.1080/01694243.2012.727168

Mohanraj, V. J., and Chen, Y. (2006). "Nanoparticles: A review," Tropical Journal of Pharmaceutical Research 5(1), 561-573. DOI: 10.4314/tjpr.v5i1.14634

Nair, S., Pandey, K. K., Giridhar, B. N., and Vijayalakshmi, G. (2017). "Decay resistance of rubberwood (Hevea brasiliensis) impregnated with $\mathrm{ZnO}$ and $\mathrm{CuO}$ nanoparticles dispersed in propylene glycol," International Biodeterioration \& Biodegradation 122, 100-106. DOI: 10.1016/j.ibiod.2017.05.008

Papadopoulos, A. (2011). "Sorption studies of chemically modified elm wood with acetic or maleic anhydride," Journal of the Indian Academy of Wood Science 8(1), 32-36. DOI: 10.1007/s13196-011-0020-9

Qing, Y., Liu, M., Wu, Y., Jia, S., Wang, S., and Li, X. (2017). "Investigation on stability and moisture absorption of superhydrophobic wood under alternating humidity and temperature conditions," Results in Physics 7, 1705-1711. DOI: 10.1016/j.rinp.2017.05.002

Rowell, R. M. (2005). "Chemical modification of wood: A short review," Wood Material Science \& Engineering 1(1), 29-33. DOI: 10.1080/17480270600670923

Simpson, W. (1980). "Sorption theories applied to wood," Wood and Fiber 12, 183-195. Van Meel, P. A., Erich, S. J. F., Huinink, H. P., Kopinga, K., De Jong, J., and Adan, O. C. G. (2011). "Moisture transport in coated wood," Progress in Organic Coatings 72(4), 686-694. DOI: 10.1016/j.porgcoat.2011.07.011

Venkateswaran, A. (1970). "Sorption of aqueous and nonaqueous media by wood and cellulose," Chemical Reviews 70(6), 619-637. DOI: 10.1021/cr60268a001

Xie, G., Zhou, Y., Cao, Y., and Li, L. (2018). “Anti-mildew properties of copper cured heat-treated wood," BioResources 13(3), 5643-5655. DOI:

10.15376/biores.13.3.5643-5655

Xie, Y., Hill, C. A. S., Xiao, Z., Mai, C., and Hilitz, H. (2011). "Dynamic water vapour sorption properties of wood treated with glutaraldehyde," Wood Science and Technology 45, 49-61. DOI: 10.1007/s00226-010-0311-0 
Yasuda, R., Minato, K., and Norimoto, M. (1995). "Moisture adsorption thermodynamics of chemically modified wood," Holzforschung 49(6), 548-554. DOI: 10.1515/hfsg.1995.49.6.548

Article submitted: June 15, 2020; Peer review completed: August 29, 2020; Revised version received: September 9, 2020; Accepted: September 11, 2020; Published:

September 21, 2020.

DOI: $10.15376 /$ biores.15.4.8459-8471 